\title{
CONHECIMENTO E POSICIONAMENTO DE ACADÊMICOS DE ENFERMAGEM SOBRE DOAÇÃO DE ÓRGÃOS E TECIDOS PARA TRANSPLANTE ANTES E APÓS UMA AÇÃO EDUCATIVA
}

\author{
Knowledge and positioning from nursing students on organ and tissue donation for \\ transplantation before and after an educational action \\ Maicon de Araujo Nogueira', José Sandino Wandenkokem Araújoº', Lilian Cristiane da Silva Serrão², \\ Rosa Maria Salmen de Souza², Márcio Almeida Lins², Thayná Desireé Rodrigues Martins³, \\ Danielle Oliveira Maciel${ }^{4}$, Marcos Renan Miranda Neres ${ }^{4}$, Edvaldo Leal de Moraes ${ }^{5}$
}

\section{RESUMO}

Objetivo: Analisar a percepção e o posicionamento dos acadêmicos de enfermagem sobre doação de órgãos e tecidos para transplante, antes e após ação educativa. Métodos: Pesquisa descritiva, exploratória com abordagem quantitativa. Participaram da pesquisa 100 acadêmicos de Enfermagem do $7^{\circ}$ ao $10^{\circ}$ semestre do curso de bacharelado em Enfermagem, em uma instituição privada de ensino superior de Belém/PA. Resultados: Do universo de 100 participantes da pesquisa, com faixa etária entre 19 a 54 anos, a maioria possuía idade entre 34 e 39 anos, representando $23,96 \%$ da amostra, sendo $82 \%$ do gênero feminino e $53 \%$ católicos. Quanto às questões de conhecimento, houve crescimento do número de acertos após a realização da ação educativa de $67,6 \%$ para $87 \%$, assim como um aumento no percentual quanto ao posicionamento em relação à doação de órgãos e tecidos após a morte, de $82 \%$ para $96 \%$. Obteve-se um resultado positivo, na medida em que, quanto analisadas as respostas antes e após a realização da ação educativa, houve crescimento dos conhecimentos dos discentes e sensibilização quanto à importância da doação de órgãos e tecidos para transplante. Conclusão: A realidade do ensino nas instituições de ensino superior (IES) encontra-se distanciada e descontextualizada das diretrizes estabelecidas pela legislação que trata de doação de órgãos e tecidos para transplante. Entende-se ser imprescindível que o profissional tenha contato com temas polêmicos, como o processo de doação e transplante de órgãos, desde a vivência acadêmica, e busque cada vez mais se aperfeiçoar e promover discussões em seu meio de convivência. As Diretrizes Curriculares Nacionais enfatizam a necessidade e o dever das IES em formar profissionais de saúde voltados ao SUS, com a finalidade de adequar a formação às necessidades de saúde da população brasileira. Dessa forma, a temática doação de órgãos e tecidos para transplante deve ser inserida nos desenhos curriculares dos cursos de graduação, para formar profissionais capacitados e preparados para lidar com as demandas sociais.

Keywords: Doação de Órgãos e Tecidos; Estudantes de Enfermagem; Educação em Saúde.

\footnotetext{
Instituições:

${ }^{1}$ Departamento de Enfermagem Hospitalar da Universidade do Estado do Pará - UEPA. Belém/PA

${ }^{2}$ Departamento de Enfermagem Hospitalar da Faculdade Metropolitana da Amazônia - FAMAZ, Belém/PA

${ }^{3}$ Acadêmico(a) de enfermagem da Universidade do Estado do Pará. Belém/PA

${ }^{4}$ Departamento de Enfermagem Hospitalar da Universidade do Estado do Pará - UEPA. Belém/PA

${ }^{5}$ Organização de Procura de Órgãos - HCFMUSP. São Paulo/SP
}

Correspondência:

Maicon de Araujo Nogueira

Psg. Jhon Engelhard, 285 - CEP 66816-030, Pratinha II - Belém/PA

Tel: (91) 98043-6368

E-mail: enfnogueira@globomail.com

Recebido em: 01/12/2015

Aceito em: 29/12/2015

\section{INTRODUÇÃO}

O transplante de órgãos e tecidos configura-se uma forma eficaz de tratamento para as doenças crônicas e incapacitantes. Todavia, o grande desafio é fazer crescer o número de doações mediante a realização de ações educativas a fim de esclarecer a população. ${ }^{1}$

Nesse contexto, o enfermeiro é o profissional que mais passa tempo junto ao paciente e sua família, recaindo sobre ele a responsabilidade de planejar e executar ações educativas, através da transmissão de ensinamentos e estreitando os laços com o paciente e seus familiares, além de participar juntamente com o profissional médico da notificação aos familiares sobre o diagnóstico de morte encefálica (ME)s sendo que a falta dessa notificação influencia no prolongamento do tempo de espera na fila de transplantes, inviabilizando o processo de doação de órgãos. ${ }^{2}$ 
Maicon de Araujo Nogueiral José Sandino Wandenkokem Araújo, Lílian Cristiane da Silva Serrão, Rosa Maria Salmen de Souza, Márcio Almeida Lins, Thayná Desireé Rodrigues Martins, Danielle Oliveira Maciel, Marcos Renan Miranda Neres, Edvaldo Leal de Moraes

Diante do reconhecimento da importância do Enfermeiro no processo de doação e transplante de órgãos e mediante a verificação de que esses profissionais necessitam estar preparados desde a vida acadêmica para atuar nos vários contextos, surgiu a necessidade de analisar a percepção e posicionamento dos acadêmicos de enfermagem sobre o processo de doação de órgãos e tecidos para transplante, verificando o nível de informação dos graduandos, assim como as principais dúvidas, a importância da discussão sobre o tema no ambiente acadêmico e social, e a contribuição da educação em saúde para o conhecimento e sensibilização dos acadêmicos de enfermagem sobre o processo de doação de órgãos e tecidos para transplante.

Portanto, o esclarecimento e sensibilização dos acadêmicos e futuros profissionais de enfermagem sobre doação de órgãos e tecidos para transplante é imprescindível, considerando a importância do profissional da enfermagem no processo. Dessa forma, objetivamos, com o presente estudo, analisar a percepção e o posicionamento dos acadêmicos de enfermagem sobre doação de órgãos e tecidos para transplante antes e após uma ação educativa.

\section{MÉTODOS}

Trata-se de uma pesquisa, descritiva, exploratória com abordagem quantitativa. O estudo foi realizado em uma Instituição de Ensino Superior (IES) Privada de Belém-PA, no período de agosto a setembro de 2015 . Participaram da pesquisa os acadêmicos do curso de bacharelado em Enfermagem, devidamente matriculado nos $7^{\circ}, 8^{\circ}, 9^{\circ}$ e $10^{\circ}$ semestres nos turnos vespertino e noturno, de ambos os gêneros, totalizando 100 participantes.

A escolha dos períodos teve como referência o contato dos acadêmicos com a área hospitalar nas práticas e estágios supervisionados. Por sua vez, não participaram desta pesquisa os acadêmicos que não estavam devidamente matriculados no $7^{\circ}, 8^{\circ}, 9^{\circ}$ e $10^{\circ}$, e menores de idade.

A pesquisa foi aprovada pelo Comitê de Ética em Pesquisa (CEP), do Centro Universitário do Maranhão (UNICEUMA), CAAE: 47559215.0.0000.5084, número do parecer: 1.180.335, com autorização prévia da instituição e posterior assinatura do TCLE pelos participantes da pesquisa.

Para a coleta de dados, utilizou-se como instrumento um questionário auto aplicável constituído de quatro etapas: na primeira etapa, foram coletados os dados biográficos; na segunda, questões específicas referentes ao conhecimento sobre o tema; na terceira, questões sobre o posicionamento e, na quarta, a questão sobre a ação educativa. De posse do questionário e após assinatura do TCLE, cada participante respondeu as perguntas de forma manuscrita, em um tempo de 60 minutos. Após a aplicação do primeiro questionário, foram analisadas as respostas e feito o levantamento das principais dúvidas referentes ao assunto para melhor direcionar a ação educativa. O planejamento da ação educativa baseouse nas principais dúvidas e/ou erros nas respostas do questionário, assim como na manutenção de pontos chave pré-estabelecidos na literatura como principais pontos de conflitos e dúvidas.

Posteriormente, a ação educativa foi desenvolvida. Esta se constituiu de aula expositiva e dialogada, realizada por um Enfermeiro Coordenador de Transplante de um Centro de referência do Estado do Pará, enfatizando as questões do primeiro questionário, assim como conceitos, importância e dados estatísticos sobre o tema, com o objetivo de favorecer um pensamento reflexivo. Houve a aplicação de um questionário após a ação educativa, com as mesmas perguntas, acrescida da última pergunta do roteiro referente à ação educativa.

Através dos dados colhidos nos questionários, realizouse análise comparativa das respostas, antes e depois da ação educativa, que por sua vez foram traduzidas através de variáveis em processamento estatístico, realizado através dos softwares GrafTable, versão 2.0 e BioEstat $5.4 .^{3}$

A pesquisa foi realizada de acordo com os pressupostos que regulamentam pesquisa envolvendo seres humanos, contidas na resolução $n^{\circ} 466 / 2012$ do CNS. $^{4}$

\section{RESULTADOS}

Do universo de 100 participantes da pesquisa, com faixa etária entre 19 e 54 anos, a maioria possuía idade entre 34 e 39 anos, representando $23,96 \%$ da amostra, conforme apresentado na tabela 1. O segundo maior índice é composto por $20,83 \%$ de participantes e encontra-se entre 29 e 33 anos.

Tabela 1 - Frequência e percentual por faixa etária dos discentes Belém, 2015.

\begin{tabular}{ccc}
\hline Faixa etária & Frequência & Percentual \\
\hline $19-24$ & 18 & 17,71 \\
$24-29$ & 14 & 13,54 \\
$29-34$ & 20 & 20,83 \\
$34-39$ & 25 & 23,96 \\
$39-44$ & 17 & 17,71 \\
$44-49$ & 4 & 4,17 \\
$49-54$ & 2 & 2,08 \\
\hline Total & 100 & 100,00 \\
\hline
\end{tabular}

Fonte: pesquisa de campo. 2015. Qui-quadrado 
Evidenciou-se que $82 \%$ dos participantes da pesquisa eram compostos por mulheres e $18 \%$ por homens.

Do universo de 100 participantes da pesquisa, 66\% trabalhavam, em detrimento de $29 \%$ que não exerciam atividade profissional, sendo que $5 \%$ não informaram se exercem ou não tal atividade.

$53 \%$ dos participantes declararam-se católicos. Dentre as demais religiões citadas, $21 \%$ afirmaram ser evangélicos, $6 \%$ espíritas, $4 \%$ cristãos, $4 \%$ protestantes, $1 \%$ adventista e $11 \%$ declararam não pertencer a nenhuma das religiões anteriores, conforme demonstrado na tabela 2.

Tabela 2 - Frequência e percentual por religião dos discentes - Belém, 2015.

\begin{tabular}{ccc}
\hline Religião & Frequência & Percentual \\
\hline Católico & 53 & 53,00 \\
Evangélico & 21 & 21,00 \\
Espírita & 6 & 6,00 \\
Cristã & 4 & 4,00 \\
Protestante & 4 & 4,00 \\
Adventista & 1 & 1,00 \\
Sem informação & 11 & 11,00 \\
\hline Total & 100 & 100,00 \\
\hline
\end{tabular}

Fonte: pesquisa de campo. 2015. Qui-quadrado

Com relação ao meio de informação mais utilizado pelos acadêmicos, observou-se que os meios de comunicação mais representativos são a Internet $(23 \%)$ e televisão (20\%). Ressalta-se ainda que $1 \%$ dos acadêmicos utiliza o jornal como meio de comunicação; $2 \%$ utilizam televisão e jornal; $16 \%$ utilizam televisão, jornal e internet; $6 \%$ utilizam televisão, jornal, internet e outros meios; $18 \%$ utilizam televisão e internet; $1 \%$ utiliza televisão e outros; $2 \%$ utilizam jornal e internet; $4 \%$ utilizam outros meios de informação e $7 \%$ não informaram.

Quanto às questões de conhecimento através da análise das respostas dos acadêmicos, pode-se observar que antes da ação educativa os discentes apresentavam conhecimentos não aprofundados acerca do processo de doação e transplante, tendo em vista o número de erros das respostas (que alcançou uma média de $17,6 \%)$.

Sendo que, após a ação educativa, houve crescimento no número de acertos das respostas, que passou da média de $67,6 \%$ para $87 \%$, bem como ocorreu diminuição no número de erros, que passou da média de $17,6 \%$ para $11,8 \%$. Destaque-se ainda que a média de acadêmicos que não souberam responder as perguntas foi reduzida drasticamente: de $14 \%$ para $1 \%$.
Apresentamos abaixo os gráficos da análise comparativa das respostas dos discentes acerca das questões de conhecimento antes e após a ação educativa.

Quanto ao conhecimento sobre o que é morte encefálica, podemos observar que após a ação educativa, houve crescimento no número de acertos das respostas, que passou de $75 \%$ para $85 \%$, bem como ocorreu diminuição no número de erros de $23 \%$ para $15 \%$. Destaquese ainda que houve uma redução de $2 \%$ para $0 \%$ na quantidade de acadêmicos que não souberam responder às perguntas (Figura 1).

Figura 1 - Percentual em relação ao conhecimento sobre morte encefálica para os discentes - Belém, 2015.

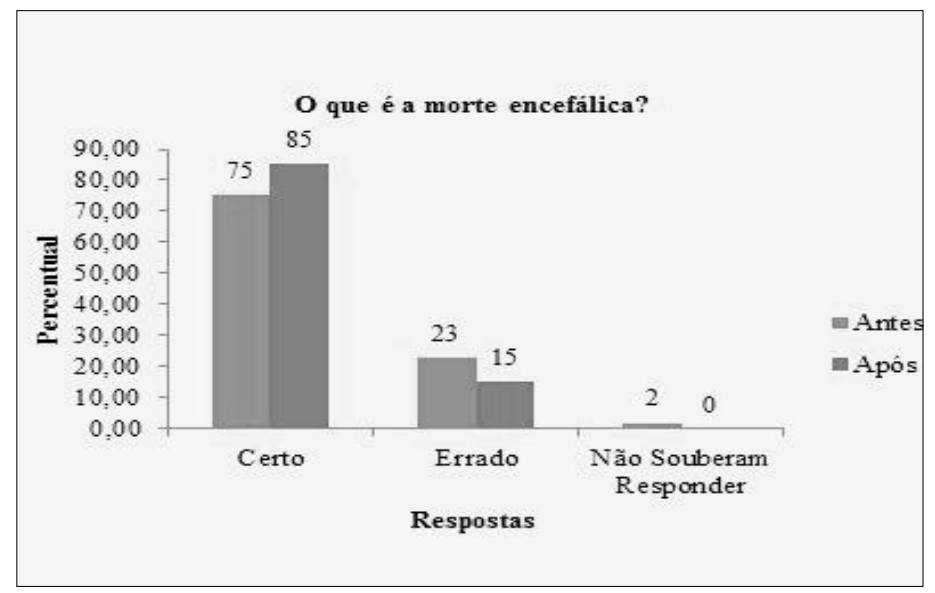

Fonte: pesquisa de campo. 2015.

Esses dados demonstram que a instrução do acadêmico de enfermagem é de extrema importância para a formação de profissionais preparados para lidar com o processo de doação e transplante, inclusive até mesmo para esclarecimentos junto aos pacientes e familiares do potencial doador (PD). Por essa razão, para procurar resolver o problema em curto prazo, devem ser promovidas ações educativas, no sentido de qualificar e sensibilizar o profissional da enfermagem, inserindo-o ativamente no processo de doação e transplante de órgãos e tecidos.

Em se tratando de diagnóstico de $\mathrm{ME}$, podemos observar que, após a ação educativa, houve crescimento no número de acertos de $42 \%$ para $80 \%$, bem como ocorreu diminuição no número de erros de $30 \%$ para $19 \%$. Destaque-se ainda que se foi obtida redução na quantidade de acadêmicos que não souberam responder às perguntas de $28 \%$ para $1 \%$.

Quando questionados sobre o que é potencial doador de órgãos e tecidos, verificou-se que, após a ação educativa, houve crescimento no número de acertos das respostas, que passou de $39 \%$ para $74 \%$, bem como ocorreu diminuição no número de erros de $26 \%$ para 
Maicon de Araujo Nogueira1 José Sandino Wandenkokem Araújo, Lílian Cristiane da Silva Serrão, Rosa Maria Salmen de Souza, Márcio Almeida Lins, Thayná Desireé Rodrigues Martins, Danielle Oliveira Maciel, Marcos Renan Miranda Neres, Edvaldo Leal de Moraes

$21 \%$. Destaque-se ainda que foi reduzida de $35 \%$ para $5 \%$ a quantidade de acadêmicos que não souberam responder às perguntas.

Observa-se que, após a ação educativa, houve crescimento de $89 \%$ para $99 \%$ no número de acertos das respostas sobre quais órgãos e tecidos podem ser doados por doador falecido, bem como diminuição no número de erros, de $5 \%$ para $1 \%$. Houve redução de $6 \%$ para $0 \%$ na quantidade de acadêmicos que não souberam responder às perguntas.

Sobre quais órgãos podem ser doados em vida, observou-se que, após a ação educativa, o número de acertos das respostas aumentou de $93 \%$ para $97 \%$, bem como ocorreu diminuição de $4 \%$ para $3 \%$ no número de erros. Destaque-se ainda que houve diminuição de $3 \%$ para $0 \%$ na quantidade de acadêmicos que não souberam responder às perguntas.

A presente pesquisa demonstra claramente que a falta de conhecimento do futuro enfermeiro sobre o tema de doação de órgãos para transplante prejudica o desenvolvimento e inserção desse profissional no processo de doação e transplante.

Além do conhecimento técnico, o profissional de enfermagem deve ter preparo emocional para lidar com a reação dos familiares de maneira ética e profissional; para tanto, necessita estar preparado desde a vida acadêmica para esclarecimento de dúvidas e para contribuir na ampliação do conhecimento do meio em que se encontra inserido.

Quando questionado se o acadêmico autorizaria sua família a doar seus órgãos após sua morte, pudemos observar, conforme o gráfico abaixo (figura 2), que houve aumento de $82 \%$ para $96 \%$ no número de pessoas que responderam sim e houve redução de $18 \%$ para $4 \%$ das pessoas que responderam não.

Figura 2 - Percentual em relação à autorização da família do discente em doar seus órgãos após a morte - Belém, 2015

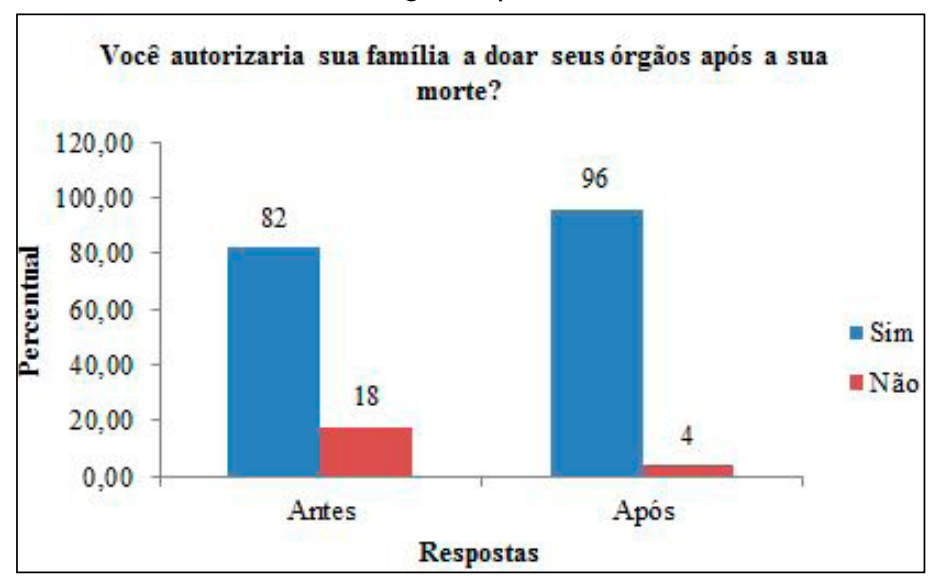

Fonte: pesquisa de campo. 2015.
Observa-se que a maioria dos acadêmicos foi favorável à doação de seus órgãos, assim como que a ação educativa possui importante papel para aumentar o número de potenciais doadores, haja vista que maior compreensão gera sensibilidade e confiança no processo de transplante de órgãos.

Observou-se a importância da educação em saúde e sua positividade para a pesquisa, considerando que após ação educativa, ocorreu o aumento de futuros profissionais sensibilizados, sendo que estes poderão contribuir para o consentimento dos familiares quando estiverem diante de um caso de ME ou de um PD de coração parado.

Quando questionado se o acadêmico autorizaria a doação de órgãos e tecidos de um familiar para transplante, observou-se que houve aumento de $71 \%$ para $88 \%$ das pessoas que responderam "sim" e houve redução de $29 \%$ para $12 \%$ das pessoas que responderam "não".

Desta forma, observa-se que, após ação educativa, ocorreu redução do número de pessoas que não permitiam a doação de órgãos e tecidos para transplante de algum familiar, inferindo-se que quanto mais se amplia o conhecimento acerca do processo de doação e transplante, mais as pessoas opinam de forma favorável a ele.

Quando questionados se o tema doação de órgãos e tecidos para transplante já havia sido conversado em sua casa, observou-se que, conforme mostrado na figura 3, houve aumento de $34 \%$ para $40 \%$ das pessoas que responderam sim e houve redução de $66 \%$ para $60 \%$ das pessoas que responderam não.

Figura 3 - Percentual sobre se o tema já foi conversado na casa do discente - Belém, 2015

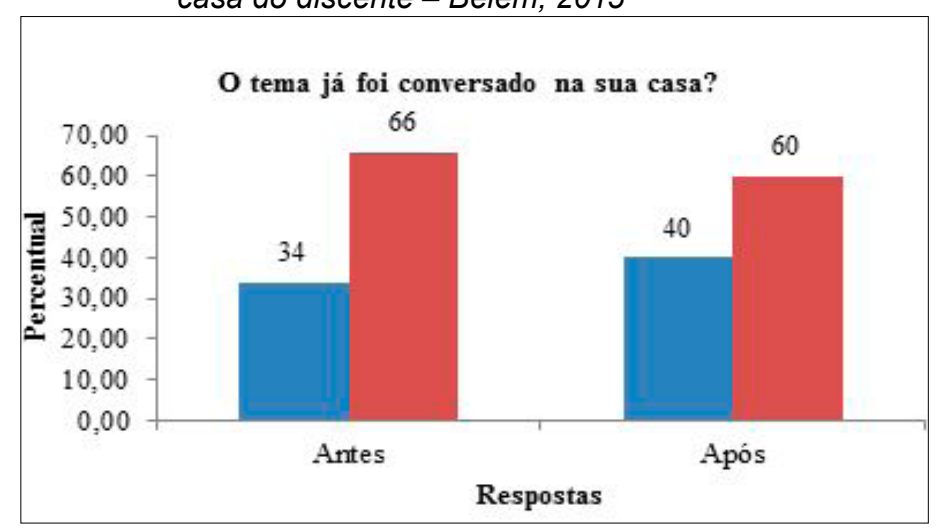

Fonte: pesquisa de campo. 2015.

Esses dados demonstram claramente a eficácia das ações educativas junto ao processo de doação e transplante de órgãos, uma vez que a presente ação educativa fez com que aumentasse o percentual de 
pessoas que falaram sobre o assunto em suas casas, o que nos leva a inferir que a ação educativa alcançou um número maior de pessoas, levando a discussão para além dos entrevistados.

Neste sentido, quando questionado se o acadêmico reconhece a educação em saúde como importante aliado no esclarecimento e sensibilização dos acadêmicos de enfermagem sobre a doação de órgãos e tecidos, a totalidade dos participantes da pesquisa respondeu que sim.

Daí, a importância do tema doação e transplante de órgãos ser abordado ainda junto ao meio acadêmico e familiar, de maneira a inserir a discussão no meio científico e na sociedade, a fim de esclarecer as dúvidas existentes, especialmente quanto ao conhecimento do correto diagnóstico de morte encefálica.

\section{DISCUSSÃO}

O presente estudo analisa o conhecimento $e$ posicionamento de acadêmicos de enfermagem sobre doação de órgãos e tecidos para transplante antes e após uma ação educativa. Foram pesquisados os acadêmicos de enfermagem dos últimos períodos por se tratarem de futuros profissionais que necessitam estar aptos para dominar o assunto desde a vida acadêmica.

$\mathrm{Na}$ amostra estudada, grande parte dos acadêmicos estava na faixa etária de 34 a 39 anos; esses dados demonstram concordância com os dados do Ministério de Educação e Cultura5 no que se refere à faixa etária da população que ingressa e/ou conclui curso de ensino superior no Brasil.

No presente estudo, $82 \%$ dos entrevistados eram do gênero feminino, o que está de acordo com os dados do Ministério de Educação e Cultura5 no que se refere à quantidade de matrículas por gênero do ensino superior, na área de saúde e bem estar social. Nesse sentido, o contingente de gênero na profissão de enfermagem aponta que a maior parte é formada por mulheres, e isso se dá historicamente, uma vez que o início da prática da enfermagem era em quase sua totalidade realizada por mulheres que se dedicavam ao trabalho assistencial, como por exemplo, a ordem das diaconisas, surgida com o advento do cristianismo. ${ }^{6}$

Dos entrevistados, $66 \%$ já possuíam experiência profissional. Nesse sentido, é possível inferir que a maioria dos acadêmicos possui experiência profissional, o que se mostra relevante para a presente pesquisa, considerando que estes já estão inseridos na rotina hospitalar e têm contato direto com pacientes, potenciais doadores (PD) e seus familiares.

Em 2013, o Conselho Federal de Enfermagem (COFEN) editou a Resolução $n^{\circ}$ 441/20137, a qual disciplina acerca do estágio supervisionado de estudantes de enfermagem e preconiza que a atividade desenvolvida pelo ou com o estudante no percurso de sua formação, sob a responsabilidade da instituição formadora, objetiva desenvolver conhecimentos, habilidades e atitudes compatíveis com o exercício profissional da Enfermagem.

A educação é uma poderosa aliada para a saúde pública, ao mesmo tempo em que é indispensável para o bom aproveitamento do processo educativo. Portanto, os investimentos nesses dois setores podem contribuir para a melhoria na qualidade de vida da comunidade. ${ }^{8}$

O percentual de católicos do estudo foi de $53 \%$; esse perfil está de acordo com os dados estatísticos da população brasileira do Instituto Brasileiro de Geografia e Estatística, ${ }^{9}$ que por sua vez demonstra que $64,6 \%$ da população brasileira declararam-se católica, sendo a segunda maior porcentagem composta por evangélicos (22\%).

A religião, sem dúvida alguma, é fator importante que interfere na opinião das pessoas acerca da doação de órgãos e tecidos para transplantes. Tudo dependerá da doutrina pertencente a cada crença religiosa que diferem entre si. Contudo, nenhuma religião é totalmente contrária à doação de órgãos e tecidos para fins de transplante. A exceção encontra-se na religião Testemunhas de Jeová, que se posiciona de maneira contrária somente com relação à doação de sangue. Apesar da maioria das religiões ser favorável ao processo de doação, ainda assim a religiosidade é fator determinante na tomada de decisões, considerando a crença do familiar na ocorrência de um milagre com o retorno à vida do paciente. ${ }^{10}$

Assim, observou-se que, apesar da religião do PD ou do familiar do PD ser determinante para influenciar na tomada de decisões, ${ }^{10}$ a quase a totalidade da amostra constituiu-se de participantes que possuem religião favorável ao processo de doação e transplante. Por mais que a religião se apresente como fator importante, não configura um entrave para o consentimento familiar. ${ }^{11}$ Isso demonstra que o enfermeiro dever ser sensível à diversidade religiosa e cultural, buscando obter conhecimento acerca dessa diversidade, a fim de realizar uma entrevista familiar qualitativa.

Em relação ao meio de informação mais utilizado, observou-se o crescente interesse da mídia em apresentar à sociedade o tema transplante de órgãos e tecidos. Porém, na maioria das vezes, ocorre a transmissão de informações em noticiários, de forma exagerada e sensacionalista, em detrimento da falta de programas esclarecedores sobre o assunto, pouco ajudando na eliminação dos mitos, o que contribui negativamente para o processo. ${ }^{12}$

Nesse sentido, observou-se que, embora as propagandas existentes na televisão objetivem estimular a doação, elas são insuficientes para esclarecer dúvidas. Com 
Maicon de Araujo Nogueiral José Sandino Wandenkokem Araújo, Lílian Cristiane da Silva Serrão, Rosa Maria Salmen de Souza, Márcio Almeida Lins, Thayná Desireé Rodrigues Martins, Danielle Oliveira Maciel, Marcos Renan Miranda Neres, Edvaldo Leal de Moraes

relação à internet, constitui-se importante meio de comunicação, considerando o amplo material existente sobre o tema, mas sem dúvida, a abordagem individual através de ação educativa possui mais receptividade para a construção de opiniões, considerando a possibilidade de ocorrer o feedback, isto é, o retorno da informação, com a possibilidade de retirada de dúvidas e prestação de esclarecimentos.

Quanto à morte encefálica, ainda são poucas instituições brasileiras que oferecem cursos de especialização ou aperfeiçoamento no Brasil, e com relação aos cursos de graduação, o que se observa é que as informações não são suficientes para a capacitação desses futuros profissionais. ${ }^{13}$ Diante disso, a formação de profissionais não qualificados nesse assunto reflete enorme prejuízo com relação à redução do número de diagnósticos de morte encefálica, ou na ocorrência desta, a falta de notificação do familiar do PD, inviabilizando o processo de doação. ${ }^{14}$

A Organização de Procura de Órgãos (OPO) ${ }^{15}$ objetiva intensificar a busca de doadores de órgãos e tecidos e, consequentemente, aumentar o número de transplantes, mas é necessário discutir acerca dos desafios que o Enfermeiro enfrenta, os sentimentos relacionados ao cuidar do paciente em ME e quais órgãos podem ser doados, a fim de propiciar condições aos membros da equipe de enfermagem para seu melhor desempenho.

Como resultado, é possível desenvolver um cuidado humanizado ao PD e seus familiares, contribuindo para o aumento do número de doações e captações efetivadas, possibilitando aumento no número de transplantes. ${ }^{15}$

Segundo a Associação Brasileira de Transplante de Órgãos (ABTO), ${ }^{16}$ a morte encefálica é definida como ausência de fluxo sanguíneo ou de atividade cerebral, levando à completa e irreversível parada de todas as funções do cérebro. Caso não ocorra o devido reconhecimento da morte encefálica, poderá haver perda do potencial doador, acabando com a possibilidade do transplante. ${ }^{17}$

O sucesso do transplante depende da organização e efetiva participação das equipes multiprofissionais e transdisciplinares em todo processo de doação, assim, as ações de diagnóstico de ME, notificação e manutenção adequadas do PD são indispensáveis para reduzir a mortalidade na lista de espera e obter sucesso nessa intervenção terapêutica. ${ }^{18}$

Oenfermeiro, juntoà equipe de enfermagem, éresponsável por realizar, durante o período de manutenção, o controle e registro de todos os parâmetros hemodinâmicos do PD. Contudo, é necessário conhecimento científico acerca das repercussões fisiopatológicas inerentes à $\mathrm{ME}$ e dos cuidados necessários para garantir as melhores condições funcionais dos órgãos e tecidos a serem transplantados. ${ }^{15}$
Os protocolos e consensos a serem seguidos pelo profissional de enfermagem têm que estar devidamente esclarecidos desde a graduação, porém, o que se observa na presente pesquisa é que, antes da ação educativa, menos da metade dos participantes tinha o conhecimento sobre o conceito de potencial doador de órgãos e tecidos.

Os órgãos passíveis de doação após a $M E$, são: rins, pâncreas, intestino, coração, pulmões e fígado. Nesse caso, também são passiveis de doação os tecidos, tais como: pele, ossos, córnea e válvulas cardíacas. ${ }^{19}$

Os graduandos de enfermagem, futuros enfermeiros, devem estar preparados e capacitados para assistir de forma integral o paciente. Para que essa assistência seja de qualidade, é necessário que o acadêmico seja preparado desde a graduação, tendo maior aprofundamento na temática na pós-graduação. ${ }^{20}$

Nesse sentido, o Conselho Federal de Enfermagem, na resolução $n^{\circ} 292 / 2004,{ }^{21}$ descreve que caberá ao enfermeiro o planejamento, execução, coordenação supervisão e avaliação dos procedimentos prestados ao doador, planejando e implementando ações para aperfeiçoar a doação de órgãos e tecidos para transplante.

Assim, através da presente pesquisa, observou-se que, embora tenham participado da pesquisa acadêmicos prestes a concluir a graduação, em sua maioria, não detinham conhecimentos básicos acerca do tema, situação que não é diferente de alguns profissionais da área da saúde. A literatura mostra evidências sobre a falta de conhecimento suficiente dos profissionais de saúde brasileiros acerca do tema, o que pode justificar o baixo nível de captação de órgãos. ${ }^{22}$

$\mathrm{Na}$ maioria dos casos, a escassez de órgãos para transplante é atribuída à falta de informação da população e às falhas no Sistema Único de Saúde no processo de captação de órgãos, contudo, essa carência também se deve a outros fatores, dentre eles, os problemas culturais, a demora no diagnóstico de $M E$, abordagem inadequada do PD, recusa da família e problemas no transporte dos órgãos. ${ }^{23}$ Dados da Associação Brasileira de Transplantes de Órgãos, ${ }^{24}$ apontam que $44 \%$ das doações que não são efetivadas devem-se à recusa familiar.

Observou-se que, conforme se aprofunda o conhecimento da população sobre doação e transplante de órgãos, o que aconteceu no presente estudo através da ação educativa, a opinião é influenciada de maneira a aumentar o interesse e facilitar o processo de doação. ${ }^{25}$ Ressaltamos a necessidade da discussão sobre o processo de doação de órgãos com parentes e amigos, uma vez que estudos já demonstraram que as principais razões para a não doção de órgãos é a 
falta de conhecimento de como ser doador e o medo de diagnóstico errado de morte. Por outro lado, as famílias que compreendem o diagnóstico de ME são mais favoráveis à doação. ${ }^{26}$

\section{CONCLUSÃO}

A presente pesquisa demonstrou que a realidade do ensino nas instituições de ensino superior (IES) encontra-se distanciada e descontextualizada das diretrizes estabelecidas pela legislação que trata de doação de órgãos e tecidos para transplante.

Entende-se ser imprescindível que o profissional tenha contato com temas polêmicos, como o processo de doação e transplante de órgãos, desde as vivências acadêmicas, e busque cada vez mais aperfeiçoar-se e promover discussões em seu meio de convivência, seja no trabalho, em casa ou mesmo em seu ambiente de estudo.

Nesse contexto, observou-se que o Enfermeiro constitui-se um verdadeiro elo entre o hospital e os familiares do potencial doador, principalmente porque esse profissional passa maior tempo com o paciente e, consequentemente, com os familiares. É justamente essa proximidade que faz com que os familiares busquem informações com o Enfermeiro, e essa fase de elucidação, principalmente acerca da morte encefálica, é imprescindível, até mesmo para minimizar o desgaste da família, principalmente porque a discussão do tema entre amigos e familiares estimula as pessoas a buscarem informação acerca do assunto, influenciando positivamente na promoção de doação.

Portanto, os graduandos de enfermagem, futuros Enfermeiros, precisam estar preparados e capacitados para assistir integralmente o paciente diagnosticado com morte encefálica, e essa preparação deve acontecer desde a vivência acadêmica, através da inclusão da temática no contexto das instituições de ensino superior, inserindo esse futuro profissional no processo de doação e transplante de órgãos e tecidos.

As Diretrizes Curriculares Nacionais enfatizam a necessidade e o dever das IES em formar profissionais de saúde voltados para o SUS, com a finalidade de adequar a formação em saúde às necessidades da população brasileira.

Dessa forma, a temática doação de órgãos e tecidos para transplante deve ser inserida nos desenhos curriculares dos cursos de graduação, para formar profissionais capacitados e preparados para lidar com as demandas sociais, e com os questionamentos e dúvidas da comunidade na qual estão inseridos, bem como conhecerem os procedimentos que estão sob sua responsabilidade no processo de doação e transplante.

\section{ABSTRACT}

Purpose: To assess the perception and positioning of nursing students on organ and tissue donation for transplantation before and after an educational activity. Methods: descriptive and exploratory research with quantitative approaching. It participated in the research 100 nursing students from the 7th, 8th, 9th, and 10th semesters of the nursing bachelor's program in a private higher education institution in Belém/PA. Results: From 100 participants in the researched group, with ages between 19 to 54 years, the majority had ages between 34 and 39 years, representing $23.96 \%$ of the sampling, being $82 \%$ female and $53 \%$ Catholics. As to the knowledge, there was an increase in the amount of hits from $67,6 \%$ to $87 \%$ after performing an educational action, as well as an increase in the percentage as to the positioning related to the after death organ and tissue donation from $82 \%$ to $96 \%$. A positive result was attained when analyzing the answers before and after the educational action, with an increase in the knowledge of students and awareness on the importance of the organ and tissue donation for transplantation. Conclusion: The reality of teaching in higher education institutions (IHE) was found detached and decontextualized from the guidelines set by the legislation that deals on organ and tissue donation for transplantation. It is understood to be essential for the professionals to be aware on the controversial issues as to the donation and organ transplantation process from academic experiences, and searching to continuously improve and promote discussions in their environment. The National Curriculum Guidelines emphasize the need and duty of the IHE to training health professionals turned to the SUS, in order to adjust education to the health needs for the Brazilian population. Thus, the theme organ and tissue donation for transplantation should be inserted in the curriculum design of undergraduate courses to training qualified and prepared professionals to deal with social demands

Keywords: Tissue and Organ Procurement; Students, Nursing; Health Education. 
Maicon de Araujo Nogueiral José Sandino Wandenkokem Araújo, Lílian Cristiane da Silva Serrão, Rosa Maria Salmen de Souza, Márcio Almeida Lins,

Thayná Desireé Rodrigues Martins, Danielle Oliveira Maciel, Marcos Renan Miranda Neres, Edvaldo Leal de Moraes

\section{REFERÊNCIAS}

1. Aline LP, José LGS, Holf HE, Elza LS, Alacoque LE. Pensamento Lean e cuidado do paciente em morte encefálica no processo de doação de órgãos. Rev Esc Enferm USP. 2015;47(1):258-64.

2. Izaura LSF, Ana EOM, Vamilson OP, Quinídia LDAQV, Gilson VT. Morte encefálica e cuidados na manutenção do potencial doador de órgãos e tecidos para transplante. Rev Eletr Enf. [internet]. 2012 [acesso em: 8 nov 2015] 14(4):903-12. Disponível em: https://www.fen.ufg.br/fen_ revista/v14/n4/pdf/v14n4a19.pdf

3. Manuel A, Manuel AJ, Daniel LA, Alex ASS. BioEstat 5.3: Aplicações Estatísticas nas Áreas das Ciências Biológicas e Médicas. $5^{\text {a }}$ ed. Belém: Publicações Avulsas do Mamirauá, 2007.

4. Ministério da Saúde. Conselho Nacional da Saúde (BR). Resolução 466, de 12 dezembro de 2012 - Diretrizes e normas regulamentadoras de pesquisas envolvendo seres humanos. Brasília (DF): 2012.

5. Brasil. Ministério da Educação e Cultura. Censo de Educação Superior (CENSUP) 2013. [acesso em 08/11/2015]. Disponível em: https://www.google.com.br/ url? sa $=\mathrm{t} \& \mathrm{rct}=\mathrm{j} \& \mathrm{q}=$ \&esrc$=\mathrm{s} \&$ source $=$ web\& $\mathrm{cd}=2 \& \mathrm{ved}=0$ CCcQFjABahUKEwjo8j4yZPJAhVGjZAKHXL6B90\&url= http $\% 3 \mathrm{~A} \% 2 \mathrm{~F} \% 2 \mathrm{Fdownload}$ inep.gov.br\%2Feducacao superior\%2Fcenso_superior\%2Fapresentacao\%2F2014 \%2Fcoletiva_censo_superior_2013.pdf\&usg=AFQjCNGr_ cV_A_d5v9_BaBwIX̄EHFKSĀZNQ\&sig2=c5eowE5NDM_-

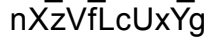

6. Andreia BSLL, Cristina NVA. A Enfermagem Brasileira: reflexão sobre sua atuação política. Rev Min de Enferm. 2013;17(2):474-80.

7. Conselho Federal de Enfermagem (COFEN). Resolução 441, de 15 de maio de 2013. Dispõe sobre participação do Enfermeiro na supervisão de atividade prática e estágio supervisionado de estudantes dos diferentes níveis da formação profissional de Enfermagem. Brasília: 2013. [acesso em: 08/11/2015] Disponível em: http://www.cofen. gov.br/resolucao-cofen-no-4412013_19664.html

8. Fernanda BA, Carmen BTLC. Educação em saúde: sensibilização de crianças por meio de estratégia de intervenção lúdica. [Trabalho apresentado ao Centro Universitário Fundação Santo André] 2013.

9. IBGE [internet]. Instituto Brasileiro de Geografia. Censo Demográfico 2010: características gerais da população, religião e pessoas com deficiência. [Acesso em: 08/12/2015] Disponível em: http://www.ibge.gov.br/home/estatistica/ população/censo2010/caracteristicas_religiao_deficiencia/ caracteristicas_religiao_deficiencia_tab_pdf.shtm

10. Marcelo JS, Maria CKBM. Fatores que facilitam a entrevista no processo de doação de órgãos e tecidos para transplante. ACTA Paul Enferm. 2011;4(24):472-8.

11. Carlos FAR, Adriano SS, Bernardo B, Guilherme SC. Morte encefálica, uma certeza? O conceito de "morte cerebral" como critério de morte. Revista Bioethikos. 2013;7(3):271-81.

12. Lisiane P, Maria HLK. Mídia e doação de órgãos: a produção de sujeitos doadores [tese]. Porto Alegre: Universidade Federal do Rio Grande do Sul; 2008.

13. Emília AC, Bartira AR, Janine S. Doação e transplante de órgãos: produção cientifica da enfermagem brasileira. Rev Bras Enferm. 2010;63(2):274-8
14. Hospital das Clínicas da Faculdade de Medicina da Universidade de São Paulo [homepage na internet]. São Pulo: Organização de Procura de Órgãos. [Acesso em: 19/01/2016]. Disponível em: http://www.hc.fm.usp.br/index. php?option=com_content\&view=article \&id=252:organizac ao-de-procura-de-orgaos-opo\&catid=23:internas.

15. Maria IFA, Tatiana OMA, Maria MSC, Emília SC, Isaura LTPR. Perfil de doadores efetivos de órgãos e tecidos no estado do Ceará. Rev Min Enferm. 2010;14(3):353-60.

16. Karina DSM, Bartira AR, Sayonara FFB, Janine S, Cristina MG. Transplante de órgãos e tecidos: responsabilidades do enfermeiro. Texto Contexto Enferm 2001;21(4):945-53.

17. Associação Brasileira de Transplantes de Órgãos. Dimensionamento dos Transplantes no Brasil e em cada estado (2006-2013). São Paulo. 2013; Ano XIX Nº 4 [Acesso em: 06/12/215] Disponível em: http://www.abto. org.br/abtov03/Upload/file/RBT/2013/rbt2013-parcial(1).pdf.

17. Marcelo JS, Edivaldo LM, Maria CKBM. Communicating bad news:ethical dilemmas before situations of encephalic death. O Mundo da Saúde. 2012;36(1):34-40.

18. Fonseca, A.T.; Costa, V. A.; Nogueira, E. C. Assistência de enfermagem ao potencial doador de órgãos e tecidos: registros de um hospital de Sergipe. J Bras Transpl. 2011;14:1449-94.

19. Brasil Escola [homepage na internet]. Importância do transplante de órgãos e tecidos. [acesso em: 15/11/2015]. Disponível em: http://www.ebc.com.br/noticias/ saude/2012/09/campanha-pretende-estimular-doacao-deorgaos.

20. Luisa GDO, Sonia N, Eronildo F, Cinthia KAA, Elizabeth MS. Modelo de avaliação do programa de controle da tuberculose. Ciência \& Saúde Coletiva. 2010;15(1):9971008.

21. Conselho Federal de Enfermagem (COFEN) Resolução COFEN 292, de 02 de maio de 2004 - Normatiza a atuação do Enfermeiro na Captação e Transplante de Órgãos e Tecidos. Brasília:2004. [acesso em: 08/11/2015] Disponível em: http://www.cofen.gov.br/resoluo-cofen-2922004_4328. html

22. Domingos GR, Boer LA, Possamai FP. Doação e captação de órgãos de pacientes com morte encefálica. Rev Enfermagem Brasil. 2010;9(4):206-12.

23. Ana LM, Adelaide MR, João PAFF, Maria HB, Michelle BR, Mithla BO. Análise das dificuldades no processo de doação de órgãos: uma revisão integrativa da literatura. Revista Bioethikos. 2010;4(1):66-74.

24. Associação Brasileira de Transplantes de Órgãos (ABTO) [homepage na internet]. Registro Brasileiro de Transplantes (RBT). 2015 [acesso em: 17/11/2015]. Disponível em: http:// www.abto.org.br/abtov03/default.aspx?c=1077.

25. Andressa SS, Flávia GS, Ivandira ARS, José SV. Transplante, doação de órgãos e tecidos: uma abordagem quantitativa e qualitativa sob a ótica dos acadêmicos de enfermagem. [Trabalho de conclusão de curso de graduação] Itajubá: Escola de Enfermagem Wenceslau Braz; 2011.

26. Bartira AR, Valter DG, Sayonara FFB, Karina DSM, Janine S. Doação de órgãos e tecidos: relação com o corpo em nossa sociedade. Acta Paul Enferm. 2010;23(3):417-23. 